\title{
The Problem of Natural Radioactive Elements
}

\author{
Andrzej Pawuła \\ Institute of Geology, Adam Mickiewicz University, Poznań, Poland \\ Email: pawula@amu.edu.pl
}

How to cite this paper: Pawuła, A. (2021). The Problem of Natural Radioactive Elements. Journal of Geoscience and Environment Protection, 9, 176-194. https://doi.org/10.4236/gep.2021.94011

Received: March 23, 2021

Accepted: April 24, 2021

Published: April 27, 2021

Copyright (c) 2021 by author(s) and Scientific Research Publishing Inc. This work is licensed under the Creative Commons Attribution International License (CC BY 4.0).

http://creativecommons.org/licenses/by/4.0/

Open Access

\begin{abstract}
The article presents two opposing views on the origin of natural radioactive elements. According to a view based on the Big Bang Theory, the elements found on Earth were formed by the process of primary nucleosyntase 13.8 billion years ago, with the exception of uranium and other heavy elements that were formed billions of years later under stellar conditions. It follows from this view that throughout the existence of the earth, the global amount of uranium and other primary radionuclides is reduced as a result of natural decay. The reasoning of the proponents of the BB theory is as follows: if the global radioactivity decreases, the problem of the threat decreases and one only needs to get used to the newly discovered natural phenomenon. There are even official regulations that exclude ionizing radiation from radon in the calculation of the limit dose. The Primary Forces of Nature theory presents a completely different view. Considering the analogous influence of gravity on the formation of the globs of the solar system, the logical explanation of the phenomena of geological activity are thermonuclear processes, such as on the sun. Hence the conclusion that the elements chemical are now created in the core of the Earth in the process of thermonuclear synthesis. The problem is serious because there is an accelerated growth of new igneous matter containing the created elements, and the ionizing radiation of natural radionuclides is the main factor responsible for the radioactivity level of the human environment.
\end{abstract}

\section{Keywords}

Radioactive Elements, Uranium Geology, Radioecology, Radon

\section{Notes on the Elements, Matter and Energy, According to the Theory of the Primal Forces of Nature}

The explanation of the origin of the elements is of particular importance in the case of natural radioactive elements, which pose an ecological threat, and their characteristic feature is the ionization effect on matter and quantitative changes 
due to natural decay. In the case of stable elements, determining the time of their formation does not matter much, it is only a topic of academic discussion. Stable elements and primary radioactive elements have similar chemical properties, the only difference between them is the instability of the atomic nucleus. The radioactivity of an element results from a large number of nucleons (neutrons and protons), which causes the state of instability of the particle. A separate group are radiogenic elements, derivatives of primary radioactive elements.

Stable elements and primary radioactive elements arise in the very process of thermonuclear synthesis. The place where the elements are created is in both cases the thermonuclear reactor. Due to natural decay, determination of the creation time is especially important for primary radioactive elements. There are over 20 primary natural radionuclides in the outer zone of the Earth (Table 1), among which two isotopes of uranium ${ }^{238} \mathrm{U}$ and ${ }^{235} \mathrm{U}$ as well as thorium ${ }^{232} \mathrm{Th}$ and the potassium isotope ${ }^{40} \mathrm{~K}$ are distinguished (Table 2).

There are two teories on the origins of radioactive elements. The first teorie explaining the creation of elements by the hypothetical Big Bang (Jarczyk, 2007) and an alternative teorie based on the operation of the Primary Forces of Nature (Pawuła, 2021), justifying the formation of elements , in thermonuclear reactions in the center of the Earth. Since radioactive elements decay naturally and their quantity decreases with time, according to the first view, the quantity of natural radioactive elements decreases and the problem of environmental radioactivity decreases. According to the second view, the amount of radioactive elements is increasing at an accelerated rate and the problem of global radioactivity is growing dangerously. According to the theory of the primal forces of nature, the interpretation of the origins of elements requires taking into account the properties of matter and its relationship with energy.

Table 1. Primary natural radioactive elements.

\begin{tabular}{cccccccc}
\hline uranium & ${ }^{238} \mathrm{U}$ & thorium & ${ }^{232} \mathrm{Th}$ & samar & ${ }^{147} \mathrm{Sm}$ & calcium & ${ }^{48} \mathrm{Ca}$ \\
uranium & ${ }^{235} \mathrm{U}$ & lutetium & ${ }^{176} \mathrm{Lu}$ & platinum & ${ }^{190} \mathrm{Pt}$ & zirconium & ${ }^{96} \mathrm{Zr}$ \\
potassium & ${ }^{40} \mathrm{~K}$ & rhenium & ${ }^{187} \mathrm{Re}$ & ind & ${ }^{115} \mathrm{In}$ & tin & ${ }^{124} \mathrm{Sn}$ \\
antymony & ${ }^{123} \mathrm{Sb}$ & rubidium & ${ }^{87} \mathrm{Rb}$ & vanadium & ${ }^{50} \mathrm{~V}$ & bismuth & ${ }^{209} \mathrm{Bi}$ \\
uranium & ${ }^{238} \mathrm{U}$ & lantalum & ${ }^{138} \mathrm{La}$ & neodymium & ${ }^{150} \mathrm{Nd}$ & tellurium & ${ }^{130} \mathrm{Te}$ \\
\hline
\end{tabular}

Table 2. Primary radionuclide content $[\mathrm{Bq} / \mathrm{g}]$

[http://www.clor.waw.pl/images/pliki/Promieniowanie_Jonizujace/artykul_1_efw.pdf].

\begin{tabular}{lccc}
\hline & ${ }^{40} \mathrm{~K}$ & ${ }^{232} \mathrm{Th}$ & ${ }^{238} \mathrm{U}$ \\
\hline mean concentration of uterine element in $1 \mathrm{~g}$ of soil & 0.420 & 0.045 & 0.003 \\
half life (T1/2) in years & $1.28 \times 10^{9}$ & $1.40 \times 10^{10}$ & $4.47 \times 10^{9}$ \\
number of radionuclides in series & 1 & 9 & 14 \\
content in the earth's crust & $7.3 \times 10^{24}$ & $7.8 \times 10^{23}$ & $5.7 \times 10^{23}$ \\
the content in the water of the oceans & $1.6 \times 10^{22}$ & $3.5 \times 10^{19}$ & $7.9 \times 10^{20}$ \\
content in $1 \mathrm{~km}^{3}$ of soil & $8.4 \times 10^{14}$ & $8.1 \times 10^{14}$ & $9.2 \times 10^{14}$ \\
\hline
\end{tabular}


The primal force of nature is gavitation, which causes clusters of matter to attract each other. Under normal conditions, matter exists on the earth's surface in three states of aggregation and has an atomic structure. As a result of the action of compressive forces, potential energy is converted into thermal energy.

It is known from physics that temperature is a measure of the kinetic energy of the random movements of molecules in matter. The consequence of the increase temperature are structural changes in matter, primo low-temperature ionization and then thermonuclear fusion reactions, changing the structure of nuclides and emitting nuclear energy. Matter changes the state of matter and acquires the properties of plasma. The action of energy on matter is manifested in the form of gamma electromagnetic radiation and alpha and beta particle radiation. Gamma radiation, depending on the energy, causes the creation of electrons in matter, or photoelectric and Compton effects. Alpha and beta radiation causes ionization of matter.

The relationship of matter with energy is expressed by Einstein's formula $E=m \cdot c^{2}$, where $m$-mass, $c$-speed of light. The mass is concentrated in elementary particles, with the atomic nucleus $10^{-14} \mathrm{~m}$ in size containing neutrons and protons. Current studies of the structure of matter show that in protons $10^{-15} \mathrm{~m}$ in size, the mass is concentrated in quarks, particles a thousand times smaller. In addition, it has been found that there is an enormous pressure inside the proton, ten times the gravitational pressure in stars.

[https://phys.org/news/2018-05-subatomic-particle-mechanical-property-reveals $\underline{. h t m l]}$

Natural, primary radioactive elements, similarly to stable elements, are formed in the Earth's core in thermonuclear fusion reactions. The origins of the elements are explained by the theory of the primal forces of nature:

- Forces of mutual attraction of masses and physico-chemical bonds;

- Electromagnetic forces affecting the properties of matter;

- Nuclear forces that appear after the disturbance of the structure of matter.

In short, the common phenomenon of gravitational accretion causes the formation of a cluster of galactic matter in the form of a globe, the mass of which is constantly increasing. The consequence of the increase in the mass of the globe is the increase in the force of gravity, the density of matter and the temperature of the globe's core. The increase in temperature causes the ionization of matter and the production of plasma. After exceeding the critical mass of the globe, the structure of matter is disturbed and the internal energy is released. The so-called mass deficit, i.e. the difference between the mass of reactants and the mass of the produced particle, is an equivalent portion of energy, defined by Einstein's formula $E=m \cdot c^{2}$, so we can say that energy is hidden in matter. Recent studies show that the pressure inside the proton is so great that it exceeds the gravitational pressure of the neutron star. Generally, it can be stated that elements, including natural radioactive elements, are created in the Earth's core and appear on its surface as a component of basalt magma.

A characteristic feature of plasma is good electrical conductivity, the ability to 
magnetize and generate a magnetic field. The increase in mass of clusters of matter is a continuous phenomenon, expressed in the domination of light nuclides, mainly protons. As the temperature increases, the proportion of protons in the plasma increases. The forming proton plasma reaches a density of $10^{7} \mathrm{~g} / \mathrm{cm}^{3}$, i.e. 10 tons per cubic centimeter. Although plasma is formed by the nuclei of a hydrogen atom, it is not a gas but a metal-like matter. Perhaps the appropriate term is "metallic hydrogen". A phenomenon accompanying the thermonuclear synthesis reaction is plasma expression and recombination.

In the fusion reactions, elements are formed, the abundance of which in the solar system is shown in the diagram above (Figure 1). Star matter is plasma, a mixture of negatively charged electrons and freely moving positive ions. This plasma consists of all nuclides, mainly protons (90\%), alpha particles (6\%), as well as electrons and solar neutrinos. A significant property of the universe's plasma is the small but stable amount of heavy nuclides with an atomic number greater than 90 , i.e. the nuclei of uranium and thorium atoms. The abundance of nuclides does not determine the type of nuclear fuel, but it is information about the final products of the processes taking place. From the presented diagram (Figure 1) it can be read that the nuclei of the uranium atom are formed in stellar reactions in the proportion of $1 / 1,000,000,000,000$ to protons.

The similarity, which proves that basalt magma is derived from hot plasma, is expressed by a wide elemental spectrum and the presence of trace amounts of uranium. The difference is the abundance of light nuclides, especially hydrogen, in the plasma and their absence in the chemical composition of the basalt rock (Table 3).

Table 3. The abundance of elements in basalt rocks (Polański, 1961).

\begin{tabular}{ccc}
\hline Main elements (8) & Minor elements (16) & Elements trace (46) \\
\hline O, Si, Al, Fe, Ca, & $\mathrm{Ti}, \mathrm{Mn}, \mathrm{P}, \mathrm{S}, \mathrm{F}, \mathrm{Ba}$, & $\mathrm{Li}, \mathrm{Be}, \mathrm{B}, \mathrm{N}, \mathrm{Sc}, \mathrm{Co}, \mathrm{Zn}, \mathrm{Ga}, \mathrm{Ge}, \mathrm{Nb}, \mathrm{Mo}, \mathrm{Pd}, \mathrm{Ag}, \mathrm{Cd}, \mathrm{In}$, \\
$\mathrm{Mg}, \mathrm{Na}, \mathrm{K}$ & $\mathrm{Rb}, \mathrm{C}, \mathrm{Cl}, \mathrm{Zr}, \mathrm{Cr}, \mathrm{Sr}$, & $\mathrm{Sn}, \mathrm{Sb}, \mathrm{Te}, \mathrm{J}, \mathrm{Cs}, \mathrm{La}, \mathrm{Co}, \mathrm{Pr}, \mathrm{Nd}, \mathrm{Sm}, \mathrm{Eu}, \mathrm{Gd}, \mathrm{Tb}, \mathrm{Dy}, \mathrm{Ho}$, \\
$\mathrm{V}, \mathrm{Ni}, \mathrm{Cu}$ & $\mathrm{Er}, \mathrm{Tm}, \mathrm{Yb}, \mathrm{Lu}, \mathrm{Hf}, \mathrm{Ta}, \mathrm{W}, \mathrm{Re}, \mathrm{Pt}, \mathrm{Au}, \mathrm{Hg}, \mathrm{Tl}, \mathrm{Pb}, \mathrm{Bi}, \mathrm{Th}, \mathrm{U}$
\end{tabular}

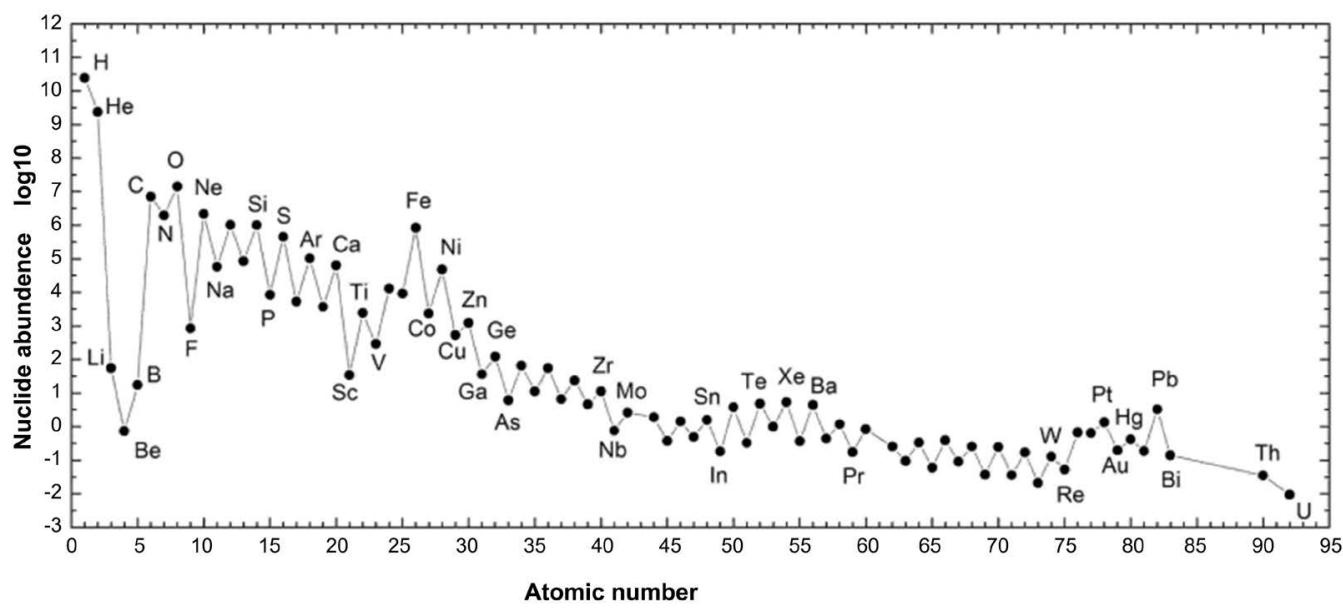

Figure 1. Nucleosynthesis products. The abundance of nuclides in the plasma of the universe. 
The reason is the transformation of protons into hydrogen gas and the rapid evolution of hydrogen as a component of volcanic gases and post-treatment solutions. During recombination, the structural change in the hydrogen gas that is formed creates enormous pressure, capable of ripping the Earth's mantle apart and expanding the globe. By attaching an electron in an orbit, the proton transforms into a hydrogen atom 100,000 times larger in diameter.

The recombination process is the reverse of the ionization process. Positive electrically charged ions combine with negatively charged electrons. The consequence of this interaction is an increase in the volume of the particle. Electromagnetic forces act between charged particles. These forces are weaker than nuclear forces but cause significant phenomena on a global scale. Attaching an electron to a proton, practically without changing the mass, causes an increase in the volume of the resulting hydrogen atom. A proton with a diameter of $0.000017 \mathrm{~A}$ ( 1 angstrom $=1 \mathrm{E}-10 \mathrm{~m}$ ), after capturing an electron, forms a hydrogen atom with a diameter of $1.1 \mathrm{~A}$. Changing the properties of matter causes a rapid increase in pressure (Pluta, 2020).

Evidence of this phenomenon is the elemental composition of basalt and hot plasma. Basalt is similar to hot plasma in a wide variety of elements, but the difference between them is the amount of proton and hydrogen. Protons that dominate the plasma composition, transforming into hydrogen gas, are released from the magma and appear in the form of volcanic gases or as a component of aid solutions, they take part in chemical reactions (Tables 4-6).

For comparison, in the Brant-Onondage natural gas field (Ontario), with helium content from $0.25 \%$ to $0.33 \%$ vol. the concentration of radon ranged from 4810 to $29,600 \mathrm{~Bq} / \mathrm{m}^{3}$.

Table 4. Chemical composition of volcanic gas-Mont Pélé, Martinique (Macdonald, 1972).

\begin{tabular}{cccc}
\hline Component & \% vol. & Component & \% vol. \\
\hline $\mathrm{CO}_{2}$ & 10.1 & $\mathrm{~F}_{2}$ & 3.3 \\
$\mathrm{CO}$ & 2.0 & $\mathrm{Cl}_{2}$ & 0.4 \\
$\mathrm{H}_{2}$ & 0.2 & $\mathrm{HCl}$ & 0.0 \\
$\mathrm{~S}_{2}$ & 0.5 & $\mathrm{~N}+$ rare gases & 0.9 \\
$\mathrm{SO}_{3}$ & - & $\mathrm{H}_{2} \mathrm{O}$ & 82.5 \\
\hline
\end{tabular}

Table 5. Natural gas radioactivity analyzes.

\begin{tabular}{ccccc}
\hline Deposit natural gas & $\begin{array}{c}\text { General beta } \\
\text { activity }\left[\mathrm{Bq} / \mathrm{m}^{3}\right]\end{array}$ & $\begin{array}{c}\text { General gamma } \\
\text { activity }\left[\mathrm{Bq} / \mathrm{m}^{3}\right]\end{array}$ & $\begin{array}{c}\text { Radon } \\
{\left[\mathrm{Bq} / \mathrm{m}^{3}\right]}\end{array}$ & $\begin{array}{c}\text { Hel } \\
{[\% \text { vol. }]}\end{array}$ \\
\hline Buk & 7.018 & 32090 & - & 0.1606 \\
Stęszew & 1.01 & 9138 & 107.3 & 0.012 \\
Szewce & - & 6240 & 96.2 & - \\
$\begin{array}{c}\text { Niemierzyce- } \\
\text { Piekary-Strzępiń }\end{array}$ & - & 5886 & 170.2 & 0.14 \\
\hline
\end{tabular}


Table 6. Natural gas components (Bolewice well, ZZGNiG Zielona Góra).

\begin{tabular}{cccc}
\hline Component & \% vol. & Component & $\%$ vol. \\
\hline $\mathrm{CH}_{4}$ & 35.312 & $\mathrm{H}_{2}$ & 0.0153 \\
$\mathrm{C}_{2} \mathrm{H}_{6}, \mathrm{C}_{3} \mathrm{H}_{8}$ & 9.214 & $\mathrm{He}$ & 0.03 \\
$\mathrm{~N}$ & 50.2077 & $\mathrm{Rn}-222$ & $170 \mathrm{~Bq} / \mathrm{m}^{3}$ \\
$\mathrm{CO}_{2}$ & 1.0 & $\mathrm{Hg}$ & $45-230 \mu \mathrm{g} / \mathrm{l}$ \\
$\mathrm{H}_{2} \mathrm{~S}$ & 4.013 & $\mathrm{H}_{2} \mathrm{O}$ & reservoir brine \\
\hline
\end{tabular}

Hydrogen gas is rapidly released in the pneumatolite phase from the postmortem solutions and reacts with elemental carbon and its oxides to form methane and juvenile water. At the temperature of about $500^{\circ} \mathrm{C}$, the reaction of elemental carbon with hydrogen probably takes place and methane is formed: $\mathrm{C}$ $+2 \mathrm{H}_{2} \rightarrow \mathrm{CH}_{4}$. The next reaction, this time of carbon monoxide with hydrogen, takes place at a temperature of $200^{\circ} \mathrm{C}-300^{\circ} \mathrm{C}$, at a depth of $6-9 \mathrm{~km}$; here methane and juvenile water are formed: $\mathrm{CO}+3 \mathrm{H}_{2} \rightarrow \mathrm{CH}_{4}+\mathrm{H}_{2} \mathrm{O}$. Therefore, the main component of volcanic gases is water vapor, there are also carbon dioxide and monoxide, hydrogen, hydrogen chloride, sulfur, nitrogen and rare gases, including radon. Juvenile water dilutes the igneous condensate which forms a hot brine, characterized by a wide spectrum of elements.

\section{The Origin of Elements According to the Big Bang Theory}

The standard view of the origin of elements is based on the Big Bang Theory. The BB theory appeared at the beginning of the 20th century as an attempt to explain the phenomenon of galaxies moving away. The author of this logical speculation, Georges Lemaitre, concluded from the hypothesis about the expanding cosmos that departing galaxies must have exploded from some starting point with "peculiar" characteristics. In philosophical considerations, it was assumed that before the Big Bang, neither matter nor time existed, nor did the laws of nature exist. At that time, particles of matter began to form and physical laws were established, deciding about the processes and phenomena taking place. In the model of the creation of the universe, however, there are interpretation problems, such as the aforementioned process of nucleosynthesis. According to the principles of nuclear physics, the process of nucleosynthesis takes place under the conditions of compression of matter. The hypothetical Big Bang phenomenon is a reverse process of total decompression. A surprising fact is the widespread adoption of such a fantastic theory that everything is immediately created from nothing.

It is surprising to accept a theory that is far from the exact sciences, as it is a philosophical reflection in the interpretation of the Universe. The shortcomings and imperfections of the standard Big Bang model are made up for by hypotheses such as the curvature of space-time. The theoretical assumptions of the formation process are as follows (Jarczyk, 2007): In the population of natural elements, three groups of nuclides are distinguished, with atomic numbers 1 - 5, 6 - 
28 and the largest up to 92 . Elements belonging to the first group were produced in primary nucleosynthesis, the elements of the second group are formed by fusion in stars, and the third group of elements was formed in the last stage of the development of massive stars.

The process scenario assumes that the lightest elements were formed in the early stages of the development of the universe. According to the model, $10^{-5}$ seconds after the Big Bang, when the temperature in the universe was $\mathrm{T}=3 \times$ $10^{12} \mathrm{~K}$, the universe occupied an area 1 light-year in diameter. Elementary particles, which are quarks, then joined together as a result of strong interactions. Systems consisting of the three lightest quarks formed protons or neutrons. The universe then consisted of photons, neutrinos, antineutrinos, and a small number of electrons and nucleons. In the 2 minutes after the Big Bang, protons were about 6 times more than neutrons. In $3-4$ minutes after the Big Bang, the processes leading to primary nucleosynthesis began. The basic reaction in primary nucleosynthesis is the process: $\mathrm{n}+\mathrm{p} \rightarrow \mathrm{d}+\gamma(\mathrm{E} \gamma=2.23 \mathrm{MeV})$, where $\mathrm{n}$-neutron, $\mathrm{p}$-poton, $\mathrm{d}$-deuterium nucleus and the rest are a gamma ray quantum. The deuteron synthesis process is slowed down by a competitive process, the so-called dissociation, the reverse process. Absorption by the deuterium nucleus of a photon with the appropriate energy $[d+\gamma \rightarrow n+p]$ causes the deuterium nucleus to decay into its components, i.e. proton and neutron.

Conditions that existed in the Universe 3 - 4 minutes after the Big Bang meant that only the lightest elements could be formed. The temperature dropped during the expansion. The temperature became so low that elemental atoms began to form. Electron capture processes were taking place. Also in this case, there is a competition between the electron capture process by the atomic nucleus and the dissociation process, i.e. the extraction of electrons from atomic orbits. Only about $10^{5}$ years after the Big Bang did the dissociation of atoms come to an end. The temperature in the Universe decreased to about $4000 \mathrm{~K}$.

In the original nucleosynthesis, which occurred in a very early period of the Universe's development, only very light elements were created, mainly hydrogen and helium atoms. The formation of the second group elements is related to the development of stars. $10^{5}$ years after the Big Bang, the universe was filled with gas, consisting primarily of hydrogen atoms and helium atoms $\left({ }^{4} \mathrm{He}\right)$. The above brief scenario of the formation of the Universe's matter can be supplemented with a few comments from criticism. Given the enormity of our galaxy and the existence of millions of other galaxies, it is irrelevant to consider the issue of a zero radius universe. Apart from the scientific credibility of the given physical quantities, there is a conflict between the physical state of the so-called "singularity" and the general theory of relativity. Einstein even stated that the conclusions of cosmology regarding the singular state testify to the imperfection of the theory itself, and not a "success" of cosmology (Czerny, 1995).

Despite such an improbable theory, that everything suddenly arises: space, time, matter and physical laws as a one-off phenomenon, practical conclusions are drawn which are assumed to be false. This applies, among others, to the view 
about the origin of radioactive elements. Therefore, in the considerations on the genesis of uranium and other long-lived radionuclides, it was assumed that they are elements originating from pre-Earth matter. The facts do not support this hypothesis. Comparative analysis of the global amount of alpha-emitting radionuclides with the amount of radiogenic He-4 helium produced shows that natural radioactive elements appeared relatively recently. According to calculations (Polański, 1961), the total amount of helium in the Earth's lithosphere and atmosphere corresponds to the production of alpha particles in a much shorter time than the age of the Earth. The helium He-4 paradox-the apparent deficit of helium isotopes. If we accept the thesis that uranium U-235, U-238 and thorium Th-232 do not appear with juvenile basalt magma, then 4 billion years ago there would have to be more of them, as shown in the diagram (a consequence of half-decay). Since helium on Earth is a product of the decay of radioactive elements in their ranks, there should be enough of it. Polański calculated that excluding the growth of the primary radionuclides U-235, U-238 and Th-232, the amount of helium on Earth corresponds to its production only over a period of 300 million years.

The view of the primordial origin of uranium stems from the negation for the operation of a thermonuclear reactor in the Earth's core and leads to the conclusion that the rock cycle and convective cells are closed. It can even be said that the Big Bang phenomenon, by introducing the laws of nature, does not fulfill them by itself. From the formal point of view, in accordance with the principles of scientific research, the condition for recognition of an experiment is its repeatability. In the case of the Big Bang, there is no repeatability. The effect is that the Big Bang scenario is contrary to the laws of nature and one can yet say more-it was not there at all.

\section{The Problem of Ionizing Radiation Dose}

Environmental radioactivity is a threat to organisms due to ionization and somatic and genetic effects. The sources of ionizing radiation are contamination caused by nuclear experiments, cosmic radiation, radioactive elements of exploited fossil resources and gaseous radon, which occurs in the ground air. In the average dose of ionizing radiation, $80 \%$ is radiation from natural sources, including 15\% from cosmic radiation. The remainder of the radiation dose (65\%) comes from elements of geological origin (Jaworowski, 1999). The term "radiation from natural sources" is misleading because it suggests a neutral nature of the phenomenon. In fact, the harmfulness of this radiation is even greater than that of artificial contamination. Unfortunately, there is a misinterpretation of this phenomenon, resulting from a misconception about the origin of natural radioactive elements.

Solving this problem requires a confrontation of cosmological and geotectonic theories. The subject of discussion is therefore the structure of the Earth's core and the explanation of the heat source. The main argument in this discussion is the phenomenon of ocean plate growth and the presence of uranium and the he- 
lium ${ }^{3} \mathrm{He}$ isotope in ocean basalt. The majority of human radiation dose comes from geological radionuclides. The starting elements in the four radioactive ranks are: uranium ${ }^{238} \mathrm{U}$, uranium ${ }^{235} \mathrm{U}$, thorium ${ }^{232} \mathrm{Th}$ and neptunium ${ }^{237} \mathrm{~Np}$. However, a group of elements occurs alone, including the potassium isotope ${ }^{40} \mathrm{~K}$.

Formally, for the general population, the permissible limit radiation dose is 1 $\mathrm{mSv} / \mathrm{y}$. In fact, this standard does not take into account radiation from natural sources and only applies to ionizing radiation from artificial sources. Thus, the risk of ionizing radiation comes from several sources. The most serious threat is ${ }^{222} \mathrm{Rn}$ radon and its derivatives (54\%), emitting alpha, beta and gamma radiation).

\begin{tabular}{ccc}
\hline Units of radioactivity & becquerel $(\mathrm{Bq})$ & curie $(\mathrm{Ci})$ \\
\hline Absorbed dose unit & $1 \mathrm{~Bq}=1 \mathrm{decay} / \mathrm{second}$ & $1 \mathrm{Ci}=3.7 \mathrm{E}+10 \mathrm{~Bq}$ \\
Unit of dose equivalent of the absorbed & gray $(\mathrm{Gy})$ & $1 \mathrm{~Gy}=1 \mathrm{~J} / \mathrm{kg}$ \\
WSB (Relative Biological Efficiency) & for $\beta, \gamma, \mathrm{X} \mathrm{WSB}=1$ & $1 \mathrm{~Sv}=1 \mathrm{~Gy} \cdot \mathrm{WSB}$ \\
Unit of dose rate for absorbed dose & $1 \mathrm{~Gy} / \mathrm{s}$ & for $\alpha \mathrm{WSB}=20$ \\
\hline
\end{tabular}

In the case of ionizing radiation from natural sources, even doses of 100 $\mathrm{mSv} / \mathrm{y}$ are tolerated, i.e. doses 100 times higher than the limit dose of $1 \mathrm{mSv} / \mathrm{y}$. This is a shocking observation. Correction of the view about the origin of radionuclides is urgently needed, because epidemiological studies already show numerous cases of genetic mutations in the natural environment. In the case of ionizing radiation from natural sources, even doses of $100 \mathrm{mSv} / \mathrm{y}$ are tolerated, i.e. doses 100 times higher than the limit dose of $1 \mathrm{mSv} / \mathrm{y}$. Correction of the view about the origin of radionuclides is urgently needed, because epidemiological studies already show numerous cases of genetic mutations in the natural environment.

The International Commission for Radiological Protection has defined the genetic dose as $50 \mathrm{mSv} / 30$ years, guided by the reproductive period criterion.

Ionizing radiation doses:

- Limit dose of $1 \mathrm{mSv} / \mathrm{y}$

- The genetic dose of $1.66 \mathrm{mSv} / \mathrm{y}$

- Average dose (1991) $3.6 \mathrm{mSv} / \mathrm{y}$

- Dose (at a radon concentration of $400 \mathrm{~Bq} / \mathrm{m}^{3}$ ) $10 \mathrm{mSv} / \mathrm{y}$

- Dose (at radon concentration of $4000 \mathrm{~Bq} / \mathrm{m}^{3}$ ) $100 \mathrm{mSv} / \mathrm{y}$

- Lifetime dose, average $150-300 \mathrm{mSv}$

- Lethal dose $3000 \mathrm{mSv}$ (3 Sv) (Hrynkiewicz, 2001)

Research carried out at the Central Laboratory for Radiological Protection (Pietrzak-Flis, 1999) has shown that radionuclides from the uranium-radium and thorium series enter the human body with food, with the largest amounts related to the toxic derivatives of radium: lead ${ }^{210} \mathrm{~Pb}$ and polonium ${ }^{210} \mathrm{Po}$. In the average dose of ionizing radiation in Poland, calculated by CLOR at 3.6 $\mathrm{mSv} /$ year (1991), as much as $80 \%$ of the dose is radiation from natural sources. Compared to the dose of uranium and thorium and their derivatives, absorbed with food $90 \mu \mathrm{Sv} /$ year $(0.09 \mathrm{mSv} / \mathrm{year})$, a much greater dose of radiation comes 
from gaseous radon and its derivatives. The dose from internal radiation consists of derivatives of inhaled radon accumulated in the body: lead ${ }^{210} \mathrm{~Pb}$ and polom ${ }^{210} \mathrm{Po}$ and potassium ${ }^{40} \mathrm{~K}$ (Table 7).

Radon decay products enter the lungs and bloodstream and then accumulate in various tissues of the body. The primary source of these elements is basalt magma, from which gaseous elements and minerals derived from igneous rocks and postmortem solutions emerge. Heavy radionuclides from the uranium and thorium families as well as radioactive potassium get into the human environment directly from volcanic gases or through the exploitation of fossil resources, primarily hard coal and phosphates (Kabat-Pentias \& Pentias, 1979).

The serious radon threat comes from natural sources. For example, during the eruption of Mount St. Helens in 1980, $1.1 \times 10^{17} \mathrm{~Bq}$ of radon was emitted into the atmosphere, i.e. about 3 million Ci (Zagórski, 1997), $\left(1 \mathrm{Ci}=3.7 \times 10^{10} \mathrm{~Bq}\right)$. For comparison, the phosphorus industry introduces $400 \mathrm{Ci}$ of radium into the environment each year, and as a result of the global consumption of coal, each year about $150 \mathrm{Ci}$ of radium ${ }^{226} \mathrm{Ra}$ is introduced into the atmosphere nature. An even more serious source of radioactivity in the environment are natural radioactive elements from the volcanic eruption.

Until the year 1950, before the period of experimental nuclear explosions in the atmosphere, the received radiation dose was $1.7 \mathrm{mSv} /$ year. At this dose, the probability of genetic mutations was one in a million (Jaworowski, 1964). This level was adopted by the International Commission on Radiological Protection as an acceptable genetic dose of $50 \mathrm{mSv} / 30$ years, introduced for the protection of the population in the reproductive period. In the ordinance of 1969 on the highest permissible doses of ionizing radiation, the permissible concentration of ${ }^{222} \mathrm{Rn}$ radon in the air was set at $37 \mathrm{~Bq} / \mathrm{m}^{3}$. In 1988 , the permissible radon concentration was increased to $100 \mathrm{~Bq} / \mathrm{m}^{3}$ and then to $400 \mathrm{~Bq} / \mathrm{m}^{3}$. In 1995 , the permissible radon concentration in the existing buildings was increased to 400 $\mathrm{Bq} / \mathrm{m}^{3}$ and in November 2000. The average ionizing radiation dose is about 3 $\mathrm{mSv} / \mathrm{year}$, that is about $150-300 \mathrm{mSv}$ throughout life. However, there are situations in which the radiation dose is many times higher. For example, staying in a building where, according to the law, the concentration of radon in the air is 400 $\mathrm{Bq} / \mathrm{m}^{3}$, it receives a dose ten times greater than the limit dose, i.e. about 10 $\mathrm{mSv} / \mathrm{y}$. Very high radon concentrations, in the order of several thousand $\mathrm{Bq} / \mathrm{m}^{3}$, were found in mountainous areas.

Table 7. Annual absorption and mean radiation dose.

\begin{tabular}{|c|c|c|c|c|c|c|c|c|}
\hline \multicolumn{9}{|c|}{ Average annual uptake with food of natural radioactive isotopes [Bq]. } \\
\hline${ }^{238} \mathrm{U}$ & ${ }^{234} \mathrm{U}$ & ${ }^{232} \mathrm{Th}$ & & & ${ }^{228} \mathrm{Th}$ & ${ }^{226} \mathrm{Ra}$ & ${ }^{210} \mathrm{~Pb}$ & ${ }^{210} \mathrm{Po}$ \\
\hline 6.12 & 8.37 & 1.09 & & & 4.92 & 18.6 & 43.4 & 44.0 \\
\hline \multicolumn{9}{|c|}{$\begin{array}{l}\text { Average annual effective doses from natural radioactive } \\
\text { isotopes taken with food by adult inhabitants }[\mu \mathrm{Sv}] \text {. }\end{array}$} \\
\hline${ }^{238} \mathrm{U}$ & ${ }^{234} \mathrm{U}$ & ${ }^{232} \mathrm{Th}$ & ${ }^{230} \mathrm{Th}$ & ${ }^{228} \mathrm{Th}$ & ${ }^{226} \mathrm{Ra}$ & ${ }^{210} \mathrm{~Pb}$ & ${ }^{210} \mathrm{Po}$ & Suma \\
\hline 0.28 & 0.42 & 0.25 & 0.37 & 0.35 & 5.20 & 30.4 & 52.8 & $90.0 \mu \mathrm{Sv}$ \\
\hline
\end{tabular}


At the radon concentration in the building of $16 \mathrm{~Bq} / \mathrm{m}^{3}$, the radiation dose received is $1.13 \mathrm{mSv} /$ year. At a radon concentration of $400 \mathrm{~Bq} / \mathrm{m}^{3}$, the dose increases to $10 \mathrm{mSv} /$ year, and at a concentration of $4000 \mathrm{~Bq} / \mathrm{m}^{3}$, it is about 100 $\mathrm{mSv} /$ year. The result is an increased risk of leukemia. The lethal dose for humans is about $3000 \mathrm{mSv}$ (Hrynkiewicz, 2001)!

\section{Basalt Magma, Earth Expansion}

Extreme geotectonic phenomena are the strongest arguments for the view of thermonuclear processes in the Earth's core and the production of elements there, including uranium. Such an argument is the tenfold increase in the volume of the globe in the last 280 million years and the production of $9.88 \times 10^{11}$ $\mathrm{km}^{3}$ of basalt magma during this period. The subject of discussion is still the construction of the interior of the Earth. Petrographic studies of igneous rocks, especially ocean basalts, which are characterized by the lowest concentrations of uranium and form the zone of lithosphere growth, are of particular importance.

(Figure 2) According to the classic petrographic definition, magma is hot matter composed of liquid and gas phases and crystalline phases (Żelaźniewicz \& Grad, 2009). Magma is a high temperature natural alloy containing water vapor and other gases that are kept in a dissolved state. Lowering the temperature and pressure of the magma causes the crystallization of various substances, of which, quantitatively, the most important are silicates and aluminosilicates. Basalt magma differs from other types of magma by several features: the lowest uranium content, a wide range of elements and the homogeneity of the chemical composition,

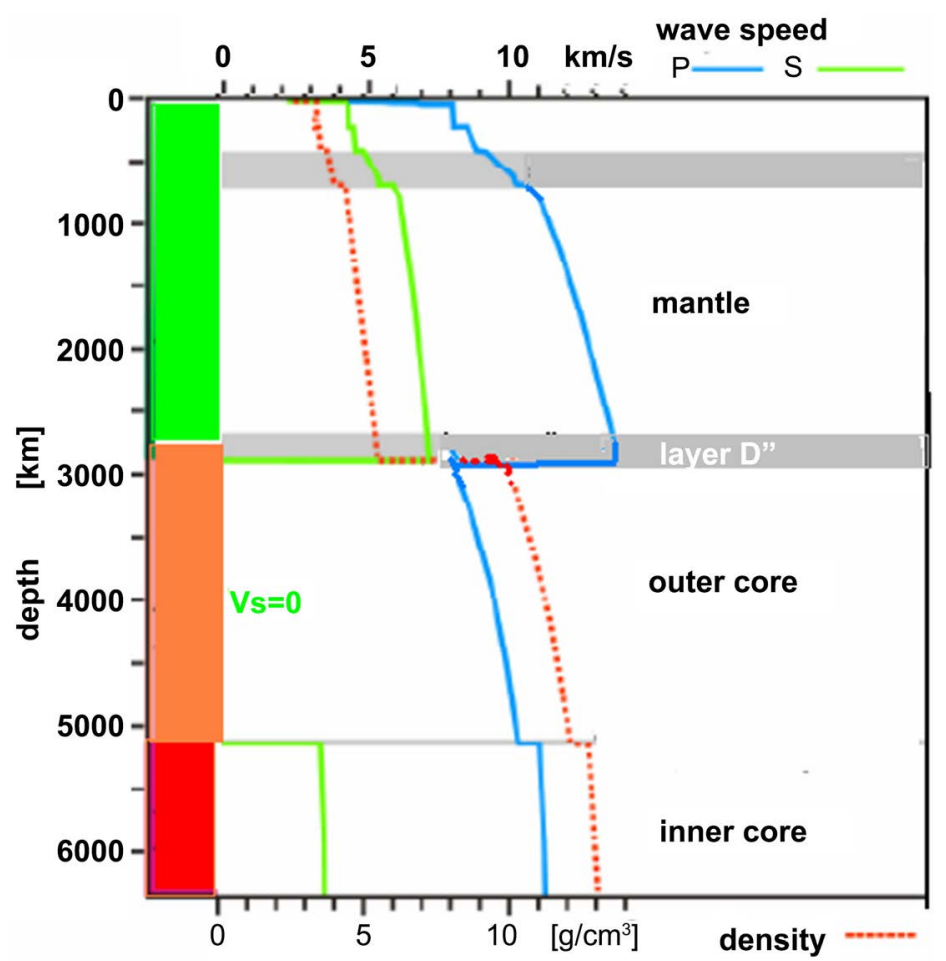

Figure 2. The geophysical profile of the Earth’s globe (Żelaźniewicz \& Grad, 2009). 
regardless of the place of discharge and the time of eruption. This proves a common source of origin. The origin of uranium is therefore associated with processes in the Earth's core, in which basalt magma is formed.

The attached global sections best illustrate the phenomenon of the Earth's expansion and the increase in the mass of the globe. In the global cross-section (Figure 3), the dominant part of the field is occupied by the nucleus, with a hard georeactor core and a layer of magnetized liquid plasma with a thickness of 2 thousand $\mathrm{km}$ and the igneous zones of the Earth's mantle growth, dated from 0 to 200 million years.

The geophysical cross-section is very suggestive, where the continents are small fragments of the globe reaching a depth of $300-400 \mathrm{~km}$ (Figure 4). The rest is built up by igneous formations, coming from basalt primary magma. The picture shows the domination of increasing igneous matter in relation to the continental plates. The traditional geotectonic theory was the Goldschmidt hypothesis of a metallic nucleus, an intermediate sulfide zone, and a silicate mantle. An alternative hypothesis was presented by Kuhn and Rittmann (1941) claiming that there is no metallic Earth's core, but that the Earth's interior is filled with undifferentiated solar matter. According to them, in the core of the Earth, apart from elements such as silicon, iron and magnesium, there is also a large amount of hydrogen. Under the influence of very high pressure, the atomic structure of magnesium silicate breaks down and transforms into a metalized state, as a result of the release of external electrons from atoms, giving a freely

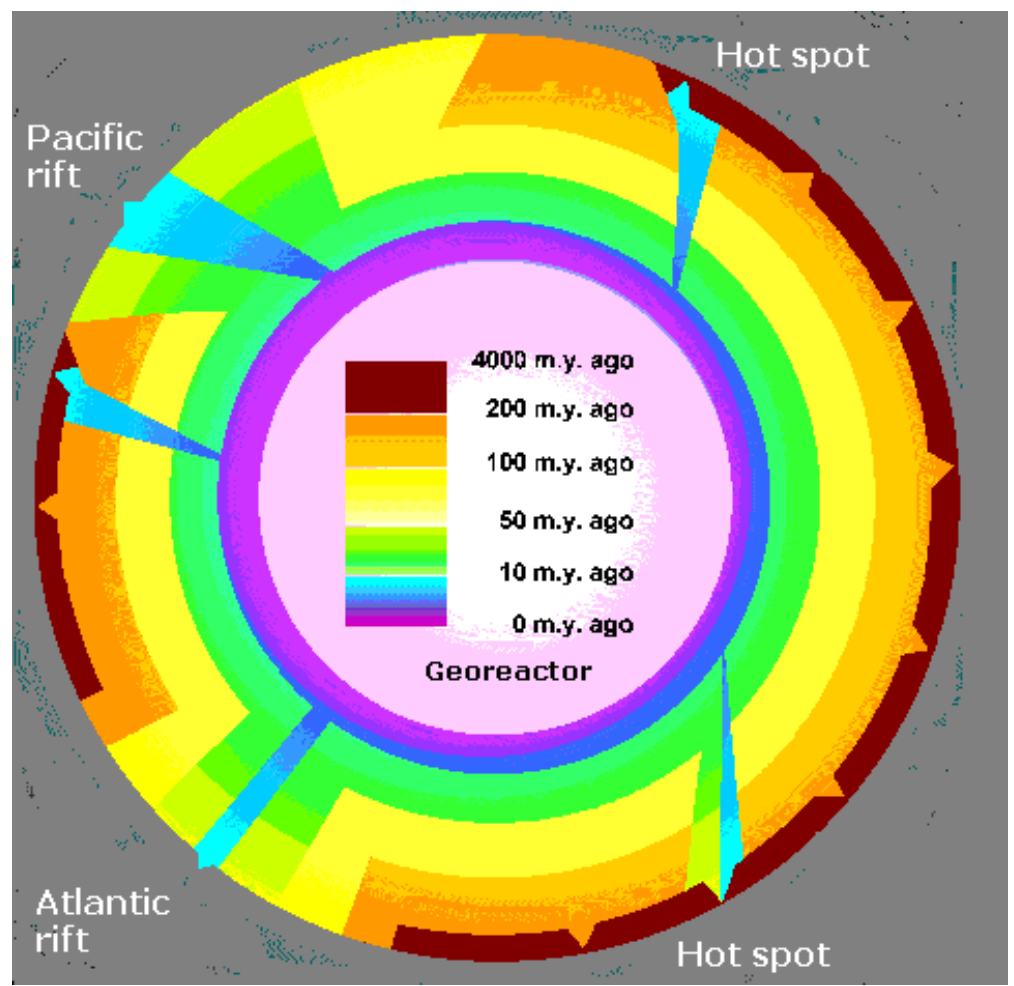

Figure 3. Mantle growth zones and ocean plates. [According to: http://www.nationalgeographic.org/tickets/events/]. 


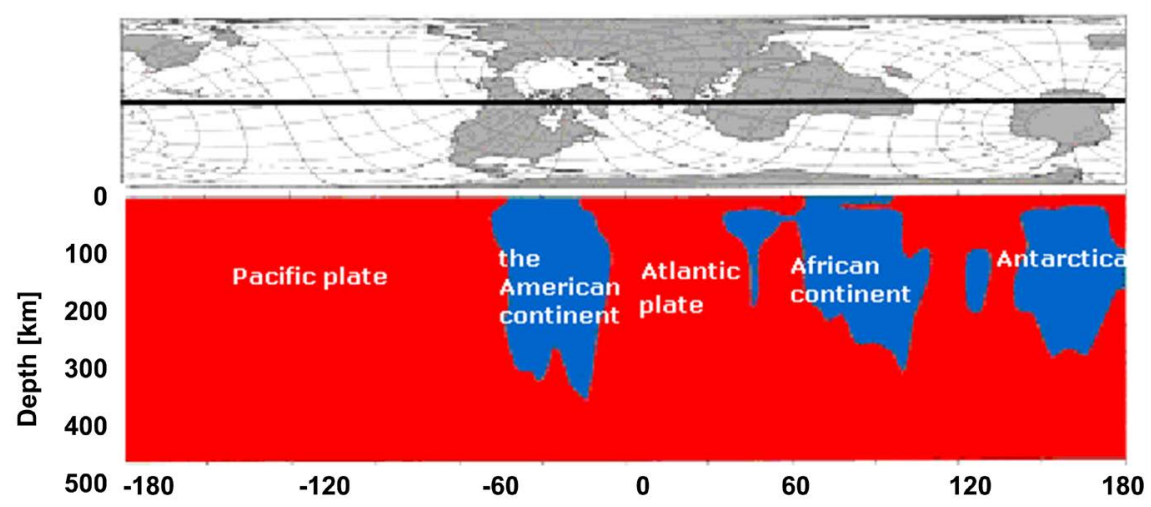

Figure 4. Continental plates in the Earth's mantle (Zhang \& Tanimoto, 1993).

moving "electron gas". This "metallization" leads to a significant and sudden increase in density. The jump in temperature and density of matter at a depth of $2750 \mathrm{~km}$ (Figure 2) confirms the earlier conclusion that new matter exists in the form of plasma.

The evidence of the emerging thermonuclear reactor is the appearance of tectonic fissures and the outflow of basalt lava (traps). An important discovery was the separation of the $\mathrm{D}$ " layer in the core of the Earth, with a thickness varying from 100 to $300 \mathrm{~km}$, constituting the lower part of the Earth's mantle. It is known that the $\mathrm{D}$ " layer is highly differentiated in terms of thermal, chemical and electrical conductivity and is believed to be the site of formation of igneous matter. Characteristic for the $\mathrm{D}$ " layer is the upward pushing of hot magma, which is marked on the Earth's surface as heat points or volcanoes. Magmatic diapirs rooted in the $\mathrm{D}$ " layer, which pierce the mantle layer, can be interpreted as initial forms of the continental rift. The total amount of basalt lava flows in the ocean rifts is estimated at 56 billion tons per year. It is estimated that about 200 million $\mathrm{km}^{2}$ of new oceanic crust has been added in this way in the last 200 million years. The bottom of the oceans, and especially the rift zone, is the area of greatest volcanic activity, for example, 1133 volcanoes have been found in the South Pacific, including about 200 active volcanoes.

Basalt magma, formed in zone D", is characterized by a homogeneous mineral composition and the presence of trace amounts of uranium $(1 \mathrm{ppm})$ and thorium (4 ppm). It is juvenile matter arising from the transformation of hot plasma. It contains the primary isotopes of uranium ${ }^{235} \mathrm{U},{ }^{238} \mathrm{U}$ and thorium ${ }^{232} \mathrm{Th}$, forming the radioactive series: uranium-actin, uranium-radium and thorium. The radioactive series ends in stable lead isotopes.

The concentration of uranium increases in the process of magma differentiation and crystallization, especially in post-displacement solutions. The wide spectrum of elements and the constant presence of uranium are evidence of the igneous origin of basalt as well as of mineral deposits. Basalt magma, made up of hot plasma in zone $\mathrm{D}$, is the primary source of uranium and thorium. The consequence of the global increase in basalt is the global increase in the amount of natural radioactive elements and thus the global increase in radioactivity. 
In conclusion, it can be stated that the process of the formation of elements in the fusion reactions takes place in the Earth's core. Natural, primary radioactive elements, uranium and thorium, are present in trace but stabilized amounts. The nuclear composition of the solar plasma is probably similar to the terrestrial plasma, and thus also to the basalt pramagma, formed in the D" zone. Confirmation of this conclusion is the homogeneous mineral composition of basalt magma and the determined concentration of uranium, at a low level of one gram per ton. The presented materials show that uranium and most of the stable elements are created in nucleosynthesis reactions (Pawuła, 2000). Terrestrial uranium comes from basalt magma, transformed from hot georeactor plasma, minimal amounts come from galactic matter (meteorites). As a result of magma differentiation, weathering and redeposition, uranium concentration increases, especially in hydrothermal deposits. Ocean plates, formed by basalt magma, cover more than $70 \%$ of the globe (Figure 5 ).

Research on the Earth's heat source indicates the existence of a thermonuclear reactor. One such argument are the geochronological analyzes of ocean basalts. The dating results clearly state that the outflowing basalt lava has a zero age, i.e. it is juvenile matter. There are no traces of melting down old rocks. If there was a process of remelting old rocks, there would be traces of long-lived radionuclides. It is surprising that the above argument is not sufficient to disprove the notion of subduction of ocean plates and convection cells. In response to the objection that it is not possible to raise the temperature of several million degrees

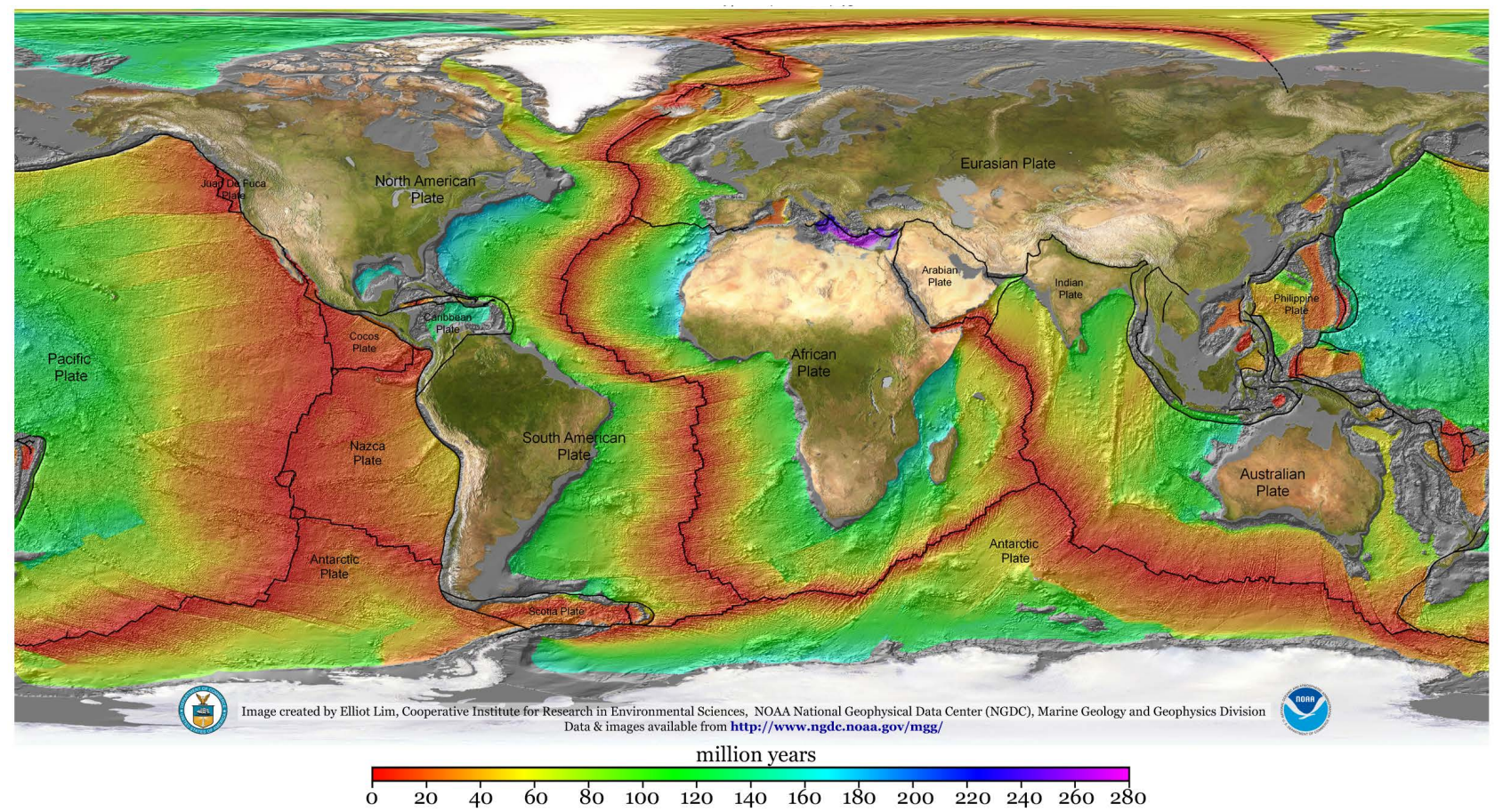

Figure 5. Mantle and ocean plate growth zones [Image created by Elliot Lim, Cooperative Institute for Research in Environmental Sciences, NOAA National Geophysical Data Center (NGDC), Marine Geologie and Geophysics Division. Data \& images available from http://www.ngdc.noaa.gov/mgg/]. 
in the center of the Earth and maintain it for the time necessary to cause an avalanche reaction of nuclide synthesis, the following explanation can be provided. The increase in the mass of the globe causes a constant increase in gravitational pressure. Thanks to the energy of cosmic rays and gravitational pressure, the temperature increases, the matter in the center of the Earth is ionized and plasma is produced. The created layer of magnetized low-temperature plasma ensures heat accumulation and reaching the temperature necessary for the initiation of thermonuclear reactions.

The study of ocean basalts in Hawaii is of particular importance. The location of the volcanoes in the middle of the ocean ensures that the lava that flows there comes from the basalt pram. Research on ocean basalt by Herndon (2003), showed their relationship with hot plasma, formed in thermonuclear reactions with the Earth's core. In the ocean water, above the submarine volcanoes, Bearman with a team of oceanologists in turn detected a zone of high helium concentration ${ }^{3} \mathrm{He}$ (Bearman, 1989), which confirms Herndon's thesis.

The presence of the helium isotope ${ }^{3} \mathrm{He}$ in volcanic gases and ocean basalt clearly indicates the operation of a georeactor in the center of the Earth, just as the presence of this isotope in the solar plasma was the basis for Eddington's discovery of a thermonuclear reactor in the Sun (Eddington, 1926).

It can be assumed that the natural radioactive elements uranium, thorium and radiopotas, appeared in the surface zone of the Earth, in basalt eruptions 280 million years ago, as a result of the expansion of the globe. This moment is marked by an increase in the radius of the Earth, and the growth curve has the form of an exponential function (Figure 6). Part of this magma froze on the ground surface in the form of basalt rocks, and a much larger part crystallized in deep sea conditions, creating a series of igneous rocks and emitting igneous gases and post-treatment solutions. Basalt magma has special properties, it is homogeneous, identical regardless of the age and place of outflow, and its elemental

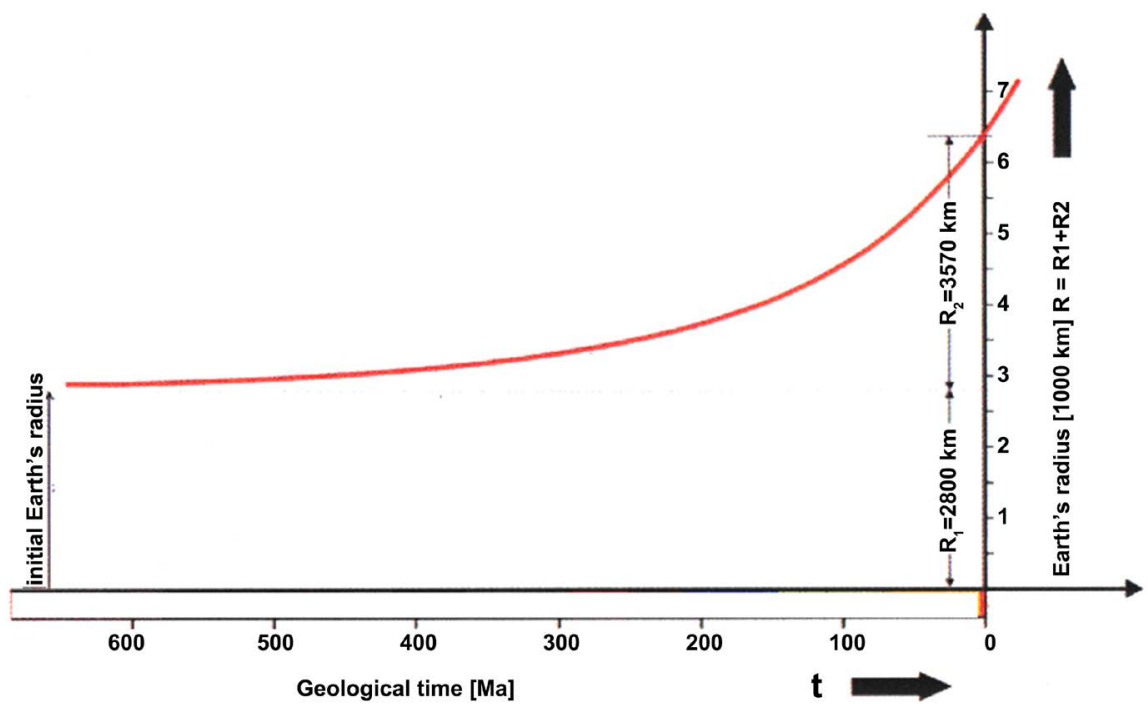

Figure 6. Earth radius growth curve (Koziar, 2018). 
composition is similar to solar plasma. Like solar plasma, it contains a wide spectrum of rare elements and small but fixed amounts of uranium and thorium. There is, however, a characteristic difference: the light elements in the basalt magma are missing, such as hydrogen, nitrogen and carbon, which were dominant in the plasma. After transformation into atomic matter, these elements constitute the gas phase of the magma.

The expansion of the Earth is expressed by an increase in the volume of basalt magma, which forms the mantle of the globe and oceanic plates. The question remains by Hildenberg (1974), does expansion occur with or without an increase in mass? The process of matter recombination is based on structural changes of matter particles, causing changes in their volume without changing their mass. In this process, the forces of the electromagnetic field act, which can create enormous tectonic pressures. You can imagine the magnitude of the pressure caused by the recobination of protons into hydrogen gas. The attachment of an electron, which is electrically charged and low in mass, creates a hydrogen atom with a volume 100,000 times larger than the proton. Knowing the phenomenon of a cracked steel pipe from experience, under the influence of water crystallization, one can imagine the effects of the structural change of a proton into a hydrogen atom. Undoubtedly, this phenomenon is the cause of global cracks, seismic tremors and volcanic activity.

Under conditions of decreasing temperature, the components of the solutions react with each other and selectively precipitate. The zones of primary uranium occurrence result from the tendency of individual chemical compounds in which uranium is present to precipitate (Figure 7).

The solution magmatic is initially a dense condensate from with the elements selectively precipitate as salts or ores. In the pegmatite stage, under residual crystallization conditions, at a depth of 18 - $30 \mathrm{~km}$, liquid magma is rich in silica, potassium and sodium (Table 8). The remains of magma conteins with vapors and gases and contain silicate components, which favors the formation of particularly large crystals. For example, in the temperature range of $700^{\circ} \mathrm{C}-850^{\circ} \mathrm{C}$, copper deposits are formed. The pneumatolytic stage, in the $12-18 \mathrm{~km}$ depth zone, is characterized by the predominance of superheated vapors over silicates and their penetration into the surrounding rocks. In the hydrothermal stage, at a

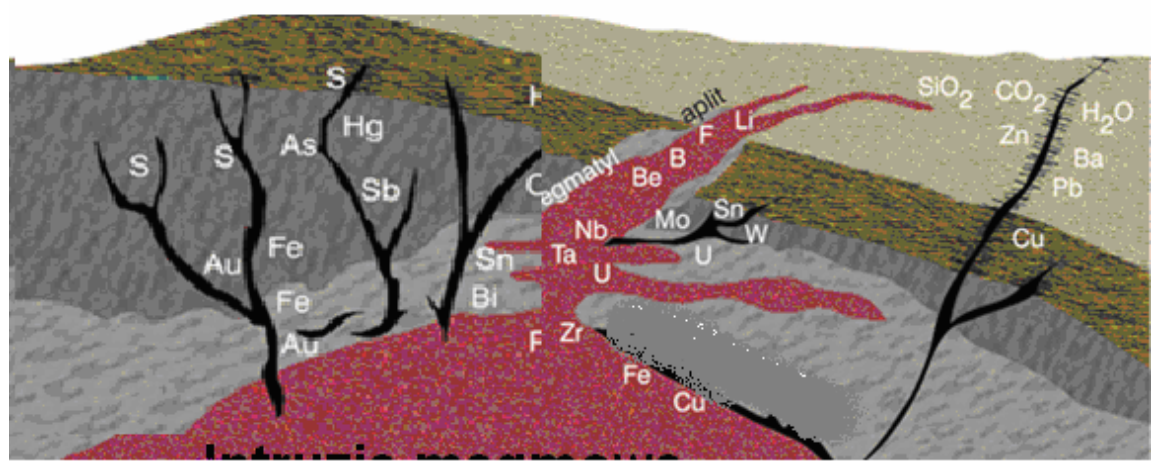

Figure 7. Igneous intrusion according to Fersman. 
Table 8. Geothermal stages (for a degree of $30 \mathrm{~m} /{ }^{\circ} \mathrm{C}$ ).

\begin{tabular}{ccc}
\hline stage & temperature range & depth zone \\
\hline igneous & $>1000^{\circ} \mathrm{C}$ & $>30 \mathrm{~km}$ \\
pegmatite & $600^{\circ} \mathrm{C}-1000^{\circ} \mathrm{C}$ & $18-30 \mathrm{~km}$ \\
pneumatolite & $400^{\circ} \mathrm{C}-600^{\circ} \mathrm{C}$ & $12-18 \mathrm{~km}$ \\
hydrothermal & $100^{\circ} \mathrm{C}-400^{\circ} \mathrm{C}$ & $3-12 \mathrm{~km}$ \\
\hline
\end{tabular}

depth of $3-12 \mathrm{~km}$, the steam condenses and the transported components gradually precipitate out of them. In the temperature conditions of $200^{\circ} \mathrm{C}-500^{\circ} \mathrm{C}$, which corresponds to a depth of $6-13 \mathrm{~km}$, chemical reactions take place between the gas components of the post-treatment solution, incl. reaction of hydrogen with carbon monoxide, producing methane and juvenile water.

Uranium precipitates from the assisting solution in several stages:

- in the pegmatite-pneumatolite stage, in pegmatites, pegmatite sulfides and molybdenites, in the temperature range $550^{\circ} \mathrm{C}-800^{\circ} \mathrm{C}$; which corresponds to a depth of $16-80 \mathrm{~km}$;

- in the hydrothermal stage, in polymetallic and tourmaline-copper deposits, at a temperature of $200^{\circ} \mathrm{C}-400^{\circ} \mathrm{C}$; depth zone $6-12 \mathrm{~km}$;

- in antimony-mercury deposits, at a temperature of $100^{\circ} \mathrm{C}-150^{\circ} \mathrm{C}$, which corresponds to a depth zone of $3-4.5 \mathrm{~km}$;

On the other hand, mercury preferably precipitates in the temperature range $50^{\circ} \mathrm{C}-100^{\circ} \mathrm{C}$. At even lower temperatures, below $50^{\circ} \mathrm{C}$, phosphates, chlorides, copper, gold, as well as zinc and lead precipitate. All of these elements come from basalt magma and that from the hot georeactor plasma.

\section{Conclusion}

The basic condition for the development of the correct assumptions of the environmental policy and environmental protection program is to identify the factors responsible for environmental pollution. Natural radioactive elements pose a serious threat. A particularly important condition for the correct interpretation of the genesis of elements is the assumption that there is a thermonuclear reactor in the center of the Earth.

The evidence of the existence of a thermonuclear georeactor are the products of its operation, basalt magma and the $3 \mathrm{He}$ helium isotope, as well as the results of geochronological research. Recognition of this fact will change view on the genesis of mineral deposits and other phenomena. The discussion on the problem of natural radioactive elements may contribute to the correction of views and administrative decisions concerning protection against ionizing radiatio, from natural sources. Accepting the view about the cosmic origin of uranium results in erroneous administrative decisions. An example is the introduction to the atomic law of the provision on not including radon radiation in the dose limit.

The core of the problem is the difference of views on the structure of the Earth's core and its role in geothermal processes. The dispute concerns the ori- 
gins of Earth's uranium. Maintaining the view that uranium is of cosmic origin results from questioning the existence of a thermonuclear reactor at the center of the Earth. Administrative decisions regarding protective measures also depend on this answer to the question about the origin of radioactive elements.

The views of the operation of a fusion reactor in the center of the Earth are therefore a test of the integrity of scientific research. Maintaining wrong views can have serious consequences. Rising levels of ionizing radiation from natural sources can, for example, threaten to emerge from various types of viral epidemics. Such a problem is already signaled in relation to animals living in the wild. Ionizing radiation from natural sources is a serious ecological threat. Without underestimating the hazard from artificial sources, the radiation hazard from natural sources should be realistically determined. There are conflicting views on the origin of uranium and the other natural radionuclides. Georadiation studies indicate an upward trend in global radioactivity. Radon emanations and other natural radioactive elements introduced into the human environment through fossil mineral resources pose a particular threat.

Unfortunately, there is interpretation of this phenomenon, resulting from a misconception about the origin of natural radioactive elements. There is a view that downplays the problem of radioactivity from natural sources, referring to the Big Bang theory. Assume due to the natural decay of elements, the amount of elements formed billions of years ago decreases and the problem disappears. The opposing view, based on the Primordial Forces theory, interprets the situation differently. The elements are created nowadays in the Earth's core, in a spontaneously formed thermonuclear reactor.

Solving this problem requires confronting inter the cosmological and geotectonic theories. The subject of discussion is therefore the structure of the Earth's core and the explanation of the heat source. The term "radiation from natural sources" is misleading because it implies neutrality nature of the phenomenon. In fact, ionizing radiation from natural sources poses a serious environmental problem. The condition for a realistic assessment of this threat is to adopt the correct geological interpretation of the Earth's core and explain the origins of chemical elements.

Extended studies of the evolution of the Earth show that a thermonuclear reactor has been formed in its core, in which the nuclide synthesis reactions take place. The phenomenon of spontaneously forming reactors is common in the Universe and is explained by the theory of the primal forces of nature. Uranium and other natural radioactive elements are present in the forming basalt magma in trace amounts, but they constantly increase global radioactivity.

\section{Conflicts of Interest}

The author declares no conflicts of interest regarding the publication of this paper.

\section{References}

Bearman, G. (1989). The Ocean Basins: Their Structure and Evolution. UK: The Open 
University.

Czerny, J. (1995). The Issue of Self-Creation of Matter in the Light of Recentivistic Theory. Folia Philosophica, 13, 171-179.

Eddington, A. S. (1926). The Internal Constitution of Stars.

Herndon, J. M. (2003). Nuclear Georeactor Origin of Oceanic Basalt ${ }^{3} \mathrm{He} /{ }^{4} \mathrm{He}$, Evidence, and Implications. Proceedings of the National Academy of Sciences of the United States of America, 100, 3047-3050. https://doi.org/10.1073/pnas.0437778100

Hildenberg, O. Ch. (1974). Debat about the Earth. The Question Should Not Be: "Drifters of Fixist?" but Instead: "Earth Expansion with or without Creation of New Matter". Geotektonische Forschung, 45, 159-165.

Hrynkiewicz, A. (Ed.) (2001). Man and Ionizing Radiation (UNSCEAR 96). Warsaw: PWN.

Jarczyk, L. (2007). The Formation of Elements in the Universe (pp. 16-27). Foton 98, Kraków: Institute of Physics of the Jagiellonian University.

Jaworowski, Z. (1964). Radioactivity and Human Health. Warsaw: PWN.

Jaworowski, Z. (1999). Radiation Risk and Ethics. Physics Today, 52, 24. https://doi.org/10.1063/1.882810

Kabat-Pentias A., \& Pentias, H. (1979). Trace Elements in the Biological Environment. Warsaw: Geological Publishing House.

Koziar, J. (2018). Geological Proofs of Significant Expansion of the Earth and Its Broader Scientific Context. Association of Geologist Alumni of Wrocław University.

Kuhn, W., \& Ritmann, A. (1941). Über den Zustand des Erdinnern und seine Entstehung aus einem homogenen Urzustand. Geologische Rundschau, 32, 215-256. https://doi.org/10.1007/BF01799758

Macdonald, G. A. (1972). Volcanoes. Hoboken, NJ: Prentice-Hall Inc.

Pawuła, A. (2000). Evolution of the Earth in the Light of GPS Measurements (pp. 25-38). Papers T.IX, Institute of Geology AMU, Polish Geological Society.

Pawuła, A. (2021). The Phenomenon of a Natural Thermonuclear Reactor. Journal of Geoscience and Environment Protection, 9, 92-109. https://doi.org/10.4236/gep.2021.92006

Pietrzak-Flis, Z. (1999). Radioactive Contamination of the Environment and Man in Poland. Department of Radiation Hygiene CLOR, Warsaw. Materials: Congress of Polish Physicists. Białystok.

Pluta, J. (2020). Nuclear Physics. Learning Materials. Institute of Physics, Warsaw University of Technology.

Polański, A. (1961). Geochemistry of Isotopes. Warsaw: Geological Publishing House.

Zagórski, Z. P. (1997). Radon-A Glance at the Whole Issue. Zakopane: Polish Society for Radiation Research Maria Skłodowska Curie, Conference Materials.

Żelaźniewicz, A., \& Grad, M. (2009). What Is Happening inside the Earth? Planet Earth Committee, Polish Academy of Sciences.

Zhang, Y. S., \& Tanimoto, T. (1993). High-Resolution Global Upper Mantle Structure and Plate Tectonics. Journal of Geophysical Research, 98, 9793-9823.

https://doi.org/10.1029/93JB00148 